\title{
A simplified method for flood risk assessment
}

\author{
G. Ciaravino \& C. Ciaravino \\ Department of Civil, Environmental and Architectural Engineering, \\ University of Naples Federico II, Italy
}

\begin{abstract}
The development of simple methodologies for the management and risk assessment of flood events is a topic of interest for administrators, economists and engineers. In this paper, flood prone areas are identified on the basis of codified return periods of flood events, leading to the identification of appropriate river bands, relative to determining the most appropriate measures in territorial planning and risk mitigation. Hydraulic risk is determined by evaluating the expected damage to vulnerable elements - first and foremost anthropic elements - resulting from the occurrence of an event of known hazard. The risk is determined by means of matrixes that, even if characterized by intrinsic limitations, make it fairly straightforward to estimate a small number of parameters and hence evaluate risk level and attention level in flood phenomena. Keywords: flood risk, flood-prone area, risk matrix, risk assessment, potential damage.
\end{abstract}

\section{Introduction}

Human settlements have been built near water bodies since ancient times and such a choice has ensured survival, development and progress. Subsequently the demographic increase combined with rising land prices due to the shortage of building areas, has led to a disordered and indiscriminate land use with all kinds of installations being built in areas at high risk of flooding. These circumstances, in conjunction with insufficient monitoring and maintenance of the territory as well as the modification of drainage networks, deforestation and topographical changes, have altered both the hydraulic and the environmental equilibrium. More recently, among other things, climate change has modified the impact of extreme hydrological events. Consequently, the increased frequency and intensity of flood phenomena, along with their rising hazard due to greater 
vulnerability of anthropic elements, has attracted the attention of central and local authorities, economists, research groups and engineers. In general it is possible to identify two questions:

- hydraulic researchers and engineers are generally interested in techniques and mathematical models that are able to estimate, both the intensity of a flood event (of given return period T and risk R) and the propagation of such a flood through the hydrographical network with the aim of achieving floodprone area mapping; however their increasingly sophisticated models may at times be somewhat complex to apply;

- central and local authorities and economists, on the other hand, require simple and instantly applicable tools for the purpose of: (i) flood risk area identification (insurance); (ii) evaluation of suitable risk mitigation work (cost-benefit); (iii) setting up of warning systems (prevention).

Moreover, legislative safeguards and preventive actions aim to protect the environment from physical deterioration and reducing its vulnerability particularly when the human sphere is exposed to hydraulic risk.

Normally the categories of elements at risk considered are [1]:

- built-up areas and their designated urban expansion areas;

- manufacturing areas, major hi-tech plants;

- infrastructure network and strategic transportation lines (both local and regional/national);

- important environmental areas and heritage sites;

- public and private sector utilities and services, sport and leisure facilities, hotels, etc.

For these categories a preliminary analysis needs to be performed in order to assess the main functional characteristics as well as the potential interference (critical sections) that can arise along the various stretches of the hydraulic network when a flood event occurs.

\section{Simplified method for flood-prone area identification}

The identification and delimitation of flood risk areas - required for the optimal implementation of mitigation work and directives safeguarding the local territory - are normally achieved through analysis of past occurrences and estimates of potential future events (hazard). Technical practice therefore tends to refer to events with a given return period $\mathrm{T}$, indicating the mean time span within which a certain event might statistically occur and be overcome once.

Because hydraulic transport phenomena are dependent upon the morphological processes of erosion, solid transport and subsequent deposition, a preliminary geomorphological classification of the river network should first be conducted in order to determine the characteristics of flood-plain river stretches.

This classification aims primarily to identify:

- the river's upland (mountain) course, which cuts through strongly cohesive soils and can either destabilize the slopes at the foot of which it flows or can be subject to a concentrated solid inflow which may give rise to flood phenomena; 
- $\quad$ the river's middle (piedmont) course, which is typically subject to deposition and may give rise to flooding if it receives considerable quantities of debris from the upstream stretches;

- the river's lowland (plain) course, located in the flood-plains which are composed of soils whose morphology is such as to allow the passage of flows corresponding to return periods of $\mathrm{T}=2 \div 5$ years without the river bursting its banks, while greater flow rates (and greater values of $\mathrm{T}$ ) may give rise to flooding.

In technical practice the mathematical computation models that are adopted for the definition of propagation phenomena and possible flooding, are characterized by different complexity according to the case under examination.

In the mountain river stretches (which are often completely dry or have a modest flow from springs), significantly dangerous flow rates are related to weather events which, because of the considerable slopes and the presence of a soil covering and/or water erosion of the mountain sides, can at times result in unpredictable solid transport phenomena (debris flow). In actual fact, the discontinuous and unpredictable hydraulic nature of these stretches, combined with a considerable solid transport capability, can create serious safety problems for towns or infrastructure situated in downstream areas.

For mountain stretches (which can be considered highly incised and steep) and excluding extreme solid transport phenomena such as debris flow, a simplified hydraulic approach can profitably be used based on (i) flow characteristics in each of the critical sections, assuming conditions of uniform flow or critical state, and (ii) assessments of the stream flow between bridge piers and through drains both in free and in submerged flow conditions.

In the stretches which have been defined as the piedmont course (characterized by steep slopes, frequently near critical slopes), and in the plain course (generally characterized by mild slopes), it is normally worthwhile to use more complex mathematical models that make it possible to evaluate the submerged flow effects caused by structures and/or morphological variations in the river bed [2]. In this case, where flooding may concern large-scale valley areas (therefore with considerable impact from a social and economic point of view and, above all, on human safety), morphological models can be employed in two-dimensional non steady flow with a comparative estimate of the flood volumes. However, in practice it is often the case that the limited topographical data make the use of such two-dimensional models vain, as they do not provide appreciably better results than the ones that could be obtained by means of a simple, but well-applied, one-dimensional model [3-5]. In actual fact, for the identification of propagation phenomena and any flooding in longer piedmont and plain stretches, especially for fairly gentle longitudinal slopes and floods of significant duration, a one-dimensional mathematical model can be profitably employed [6]. Such a model would assume only slight variations of boundary conditions over time, and is based on a succession of events of steady flow (quasi-stationary approach). These models are essentially based on the hydraulic equations of motion and continuity under the hypothesis of constant fluid density: 


$$
\begin{aligned}
& \frac{d E}{d x}=-J \\
& \frac{d Q}{d x}=q
\end{aligned}
$$

Equation (1) expresses the principle by which the variation in specific energy $E$ (defined by Bernoulli's equation) of the stream flow per unit of distance travelled is equal to the continuous and unitary losses $J$. The continuity equation (2) establishes the balance between masses (or, as in this case, between volumes) entering and leaving the elementary section $d x$, indicating with $q$ the lateral uniform flow. These equations are coupled with theoretical and/or experimental relations for assessing the parameters they contain as a function of the mean velocity $V$ and the water depth $h$ which are identified as the main unknown quantities in the calculation process. In particular, the relations define the assessment of the continuous head losses, the stream flow's Froude number, the transport capacity of the individual sections, and the non-uniformity of the local mean velocities [7-13].

In technical practice the system of differential equations (1) and (2) is solved (as it is not always solvable by analytical methods) with a numerical approach by discretizing the system itself in the following single equation:

$$
z_{x}+h_{x}+\frac{\alpha_{x} \cdot Q_{x}^{2}}{A_{x}^{2} \cdot 2 g}=z_{x+\Delta x}+h_{x+\Delta x}+\frac{\alpha_{x+\Delta x} \cdot Q_{x+\Delta x}^{2}}{A_{x+\Delta x}^{2} \cdot 2 g}+J_{m} \cdot \Delta x
$$

where, at the generic progressive coordinate $x$, beyond the already defined symbols, $z$ is the bed height referred to a generic horizontal plane, $h$ is the corresponding water depth, $A$ is the cross section, $g$ is gravity acceleration, $\alpha$ is Coriolis coefficient and $J_{m}$ is the mean value of energy line slope. In general, moreover, it is possible to define the following relationships:

$$
\begin{gathered}
A=A[h(x)] \\
\alpha=\alpha[h(x)] \\
J_{m}=f\left[J_{x}, J_{x+\Delta x}\right]=f^{\prime}[h(x), h(x+\Delta x), V(x), V(x+\Delta x)]
\end{gathered}
$$

where, in equation (6) $V$ is mean flow velocity univocally linked to $h$ by means of equation (2); therefore in equation (3) the value of $h_{x+\Delta x}$ is the only unknown quantity. Indeed, for each calculative step, once assigned the values of $h$ and $V$ (and therefore the value of $Q$ ) at coordinate $x$, through relationships (4), (5) and (6), by successive attempts the values of $h$ and $V$ (and therefore of $Q$ ) can be calculated referred to the coordinate $x+\Delta x$ so that equation is satisfied.

The flow rates, taken as a basis for the hydraulic tests to identify and delimit the hydraulic risk areas, are normally determined using a statistical method based on given return periods $T$. The lack or inadequacy of field data on river flow rate values almost always leads to these flow rates being deduced from pluviometric 
probability curves linking the mean annual maxima for precipitation of given duration to the duration itself.

The statistical methods which are adopted are numerous and different depending on the country and geographical area; however the aim is to assess the maximum flood flow rate $Q_{T}$ corresponding to the fixed return period $T$. For example a method accepted in many Italian administrations provides regional hydrological analysis of extreme rain values based on the use of Two Component Extreme Value (TCEV) [14]. The value of $Q_{T}$ is determined starting from the estimate of a reference flow rate $Q_{M}$, called index flow rate, corresponding to the mean of distribution of annual maximum of flood flow rate:

$$
Q_{T}=K_{T} \cdot Q_{M}
$$

where $K_{T}$ (ratio $Q_{T} / Q_{M}$ ), known as a regional probabilistic growth factor, assumes a value that is variable over $T$ and is assessed by means the regional hydrological analysis; therefore once calculated $Q_{M}$ (e.g. with direct method based on monomial equations; with indirect method through geomorphoclimatic model or rational model) $Q_{T}$ is assessed. The choice of the reference return period $T$ is usually related to the characteristics of the territory and the existing or planned structures in it, as well as any criteria required by law. For the above mentioned categories at risk $[1,15]$, it is possible to choose flow rates corresponding to values of $T=5, T=30, T=100, T=300$ years. The application of simple computation models makes it possible to clearly identify flood-prone areas in flooding events with given return periods $T$. Thus it is possible to define:

- $\quad$ areas with a high frequency of flooding for return periods $T \leq 30$ years;

- $\quad$ areas with a medium frequency of flooding for return periods $30<T \leq 100$ years;

- $\quad$ areas with a low frequency of flooding for return periods $100<T \leq 300$ years.

In these areas it is possible to distinguish between areas that are subject to direct flooding (adjacent to the river body), areas prone to flooding by upstream flows (also with transport of miscellaneous material), areas prone to flooding because of structures limiting flow (e.g. bridges with insufficient distance between piers, constrictions and/or obstructions, etc.). On this basis river bands are defined which may be subject to flooding depending on geomorphological characteristics of the terrain. Consequently it is possible to organise territorial planning and management activities.

A first band, which is defined Band $0(B 0)$, coincides with the ordinary flood channel, defined as the part of the water body involved in the flow of an ordinary flood corresponding to a return period $T=2 \div 5$ years. In the case of morphologically encased channels, this band coincides with the river area located between the banks while, in the case of alluvial channels, this band corresponds to erratic channels interested by the ordinary flood flow.

A second band, which is defined Band $1(B 1)$, corresponds to the standard flood channel which ensures the free flow of the so-called standard flood which is normally the value of the flood flow rate taken as the basis for the sizing of the hydraulic defence works: this value can be made to coincide with the flow rate corresponding to the return period $T=100$ years. 
A third flooding band, which is defined Band 2 (B2), corresponds to floodplain relative to the above defined standard flood flow. Band 2 can be subdivided, if needed, into flood-plain sub-bands with a return period $T<100$ years, in which the stream flow velocity will also be taken into account as this can be a useful indicator of the intensity of the flood event and may at times provide a more significant estimate than the water depths. In particular, three sub-bands are identified: Sub-band $2 \mathrm{a}(B 2 a)$ lies between the standard flood channel and the limit of water depth $h_{f}=0.30 \mathrm{~m}$ of flood with return period $T=30$ years; Sub-band $2 \mathrm{~b}(B 2 b)$ lies between the limit of Sub-band $2 \mathrm{a}$ and the limit of the water depth $h_{f}=0.30 \mathrm{~m}$ of flood with return period $T=100$ years; Sub-band $2 \mathrm{c}(B 2 c)$ lies between the limit of Sub-band $2 \mathrm{~b}$ and the limit of flood with return period $T=100$ years.

A fourth and final flooding band, which is defined Band 3 (B3), corresponds to the flood-plain at risk from exceptional flood events, such as the one with return period $T=300$ years or by historically verified floods characterised by flow rate values well in excess of the standard flood.

In actual fact, the stream flow velocity and the location of any constrictions and/or obstructions are of great importance for flood events because of the consequences that they can produce: in particular, velocity is greater (and close to that of the central channel) in the bands closest to the channel body $(B 0, B 1$ and $B 2 a)$, while it is smaller in the more external bands $(B 2 b, B 2 c$ and $B 3)$.

Therefore any obstruction will exert a greater or lesser effect not only according to its shape, size and position with respect to the direction of stream flow but also according to its position with respect to stream flow in each river band defined above.

\section{Flood risk assessment (risk matrix)}

Risk $R$ normally expresses the value of the expected damage $D$ to elements (in a category characterized by exposition $E$ and vulnerability $V$ ) present in the considered area $S$, following the occurrence of an event of given hazard $H$, being: $R=H \cdot V \cdot E[16]$.

If there are no vulnerable elements in the area, the damage and hence the risk can be considered as null. In other words, the level of risk is defined by the characteristics of the vulnerable category and the degree of hazard, i.e. the probability of an event occurring. On this basis, we can obtain an estimate of the expected damage and the risk by referring to particular conventional matrixes.

The flood-prone areas and the relative degree of hazard are identified by delimiting the previously defined river bands. In particular, in the case of hydraulic risk, the expression of hazard in area terms is provided by the flood bands, which represent the limit that flooding could reach for a given flood event; the hazard value is determined using the return period $T$. The vulnerability of elements at risk depends on their capability to sustain the stresses caused by the event and on the intensity of the event itself (water depth, stream flow velocity, dynamics of the event). Therefore, identifying flood-prone areas as defined by homogeneous categories indicating the presence of valuable elements 
- such as residential areas (assessed according to inhabitant number), buildings (assessed according to number and type), public buildings where users are constantly present, road and rail infrastructure - makes it possible to delimit areas at flood risk. In other words, overlapping between areas of various anthropic element (Anthropic Element Chart) and flood-prone areas (River Band Chart) defines the areas at different risk levels (Risk Chart). The risk $R$ is normally classified using a scale of values that estimates the expected damage to the environment and anthropic elements, focussing in particular on the direct involvement of people. Four risk levels $R$ can be defined in this way:

- $\quad R 1$ low risk: only marginal damage to the community, the environment and the economy;

- $\quad R 2$ medium risk: modest damage to buildings, infrastructure and environment is possible but people's safety is not jeopardized, buildings remain operational and economic activity is not interrupted;

- $\quad R 3$ high risk: people's safety jeopardized, functional damage sustained by buildings and infrastructure making them unserviceable, socio-economic activity is interrupted and the environment suffers major damage;

- $\quad R 4$ very high risk: possible loss of human life or serious physical injury, major damage to buildings, infrastructure and environment, destruction of socio-economic activities.

Making reference to the standard flood (taken as the basis for the sizing of the hydraulic defence works), if every type of element at risk is associated with a potential damage index $D$, by overlapping with the above defined river bands it is possible to identify the different levels of risk as indicated in Table 1, where D1 indicates low potential damage, D2 medium potential damage, D3 high potential damage, and $D 4$ very high potential damage.

Table 1: Risk matrix.

\begin{tabular}{|c|c|c|c|c|}
\cline { 2 - 5 } \multicolumn{1}{c|}{} & $B 1$ & $B 2 a$ & $B 2 b$ & $B 2 c$ \\
\hline$D 4$ & $R 4$ & $R 3$ & $R 2$ & $R 1$ \\
\hline$D 3$ & $R 3$ & $R 2$ & $R 1$ & $R=0$ \\
\hline$D 2$ & $R 2$ & $R 1$ & $R=0$ & $R=0$ \\
\hline$D 1$ & $R 1$ & $R=0$ & $R=0$ & $R=0$ \\
\hline
\end{tabular}

Under the same hypotheses, Table 2 reports the index of potential damage associated to the various category of the Anthropic Element Chart and the levels of risk derived from its overlapping with the river bands. The matrixes obtained constitute a simple tool of synthesis which, by identifying areas and levels of risk and damage, can aid:

- $\quad$ to highlight the presence of critical sections, such as bridges that risk being submerged; natural or man-made constrictions, insufficient river dams, flood-prone communication infrastructure;

- to plan structural and non-structural interventions to safeguard the local territory, such as land reclamation in hydrographic basins by means of 
hydro-geological interventions as well as in areas of forest, woodland, pasture and farmland; setting and regulation of rivers; flood management; regulation of extraction activities; hydraulic maintenance, administrative regulation; monitoring and warning systems; creation of emergency plans;

- to promote ecological interconnection of natural areas for the maintenance and/or gradual recovery of the river area complexity and biodiversity.

Table 2: Risk and damage associated to anthropic elements.

\begin{tabular}{|l|c|c|c|c|c|}
\hline & Damage & $B 1$ & $B 2 a$ & $B 2 b$ & $B 2 c$ \\
\hline Historic City Centre & $D 4$ & $R 4$ & $R 3$ & $R 2$ & $R 1$ \\
\hline $\begin{array}{l}\text { Completion and Expansion } \\
\text { Area }\end{array}$ & $D 4$ & $R 4$ & $R 3$ & $R 2$ & $R 1$ \\
\hline $\begin{array}{l}\text { Industrial and/or Commercial } \\
\text { Area }\end{array}$ & $D 4$ & $R 4$ & $R 3$ & $R 2$ & $R 1$ \\
\hline Area of Community Interest & $D 4$ & $R 4$ & $R 3$ & $R 2$ & $R 1$ \\
\hline Tourist Accommodation Area & $D 4$ & $R 4$ & $R 3$ & $R 2$ & $R 1$ \\
\hline $\begin{array}{l}\text { National and Regional } \\
\text { Protected Areas }\end{array}$ & $D 3$ & $R 3$ & $R 2$ & $R 1$ & $R=0$ \\
\hline Protected Environment Areas & $D 4$ & $R 4$ & $R 3$ & $R 2$ & $R 1$ \\
\hline Transport Infrastructure & $D 4$ & $R 4$ & $R 3$ & $R 2$ & $R 1$ \\
\hline Isolated Houses & $D 4$ & $R 4$ & $R 3$ & $R 2$ & $R 1$ \\
\hline Heritage Sites & $D 4$ & $R 4$ & $R 3$ & $R 2$ & $R 1$ \\
\hline Cemeteries & $D 3$ & $R 3$ & $R 2$ & $R 1$ & $R=0$ \\
\hline
\end{tabular}

\section{Additional observations}

As previously mentioned, flood risk is a function of the probability of flood events (hazard) and the damage that follows the flooding event. The economic value of total damage is equal to the sum of the direct damage which is a function of water depth $h$, and of indirect damage caused by the disuse of the damaged categories [17]:

$$
D_{t}=\int_{i=0}^{i=m}\left(\int_{h=0}^{h=h_{\max }} k_{i}(h) \cdot n_{i}(h) \cdot D_{i \max } \cdot d h\right) \cdot d i
$$

where $D_{t}=$ total damage; $k_{i}(h)=$ damage factor of category $i ; n_{i}(h)=$ number of units in category $i$ affected by flooding characterized by water depth $h ; D_{\text {imax }}=$ 
maximum damage for unit in category $i ; m=$ number of categories. In particular the damage factor is determined by a function of damage, relative to the categories, which depends on the water depth of flooding. Furthermore it is possible to estimate the probability $P_{T, S}$ that a flood event, corresponding to a given return period $T$, occurs within each river band. Indeed through the application of rules of composed probability the following equation is obtained:

$$
P_{T, S}=1-\left(1-\frac{1}{T}\right)^{T_{S}}
$$

where $T_{S}$ is a reference time (hazard interval) again measured in years.

In equation (9) it is possible to assign a value to exponent $T_{S}$ equal to a return period corresponding to a determined river band. In detail, once a return period $T$ is determined, $P_{T, S}$ is estimated as the value of $T s$ varies and a series of curves is obtained on the plane $T_{S}$ vs. $P_{T, S}$ (Figure 1, thick lines). In the same way, for each value of $T_{S}$ a second series of curves is obtained (Figure 1, thin lines) in the plane $T$ vs. $P_{T, S}$.

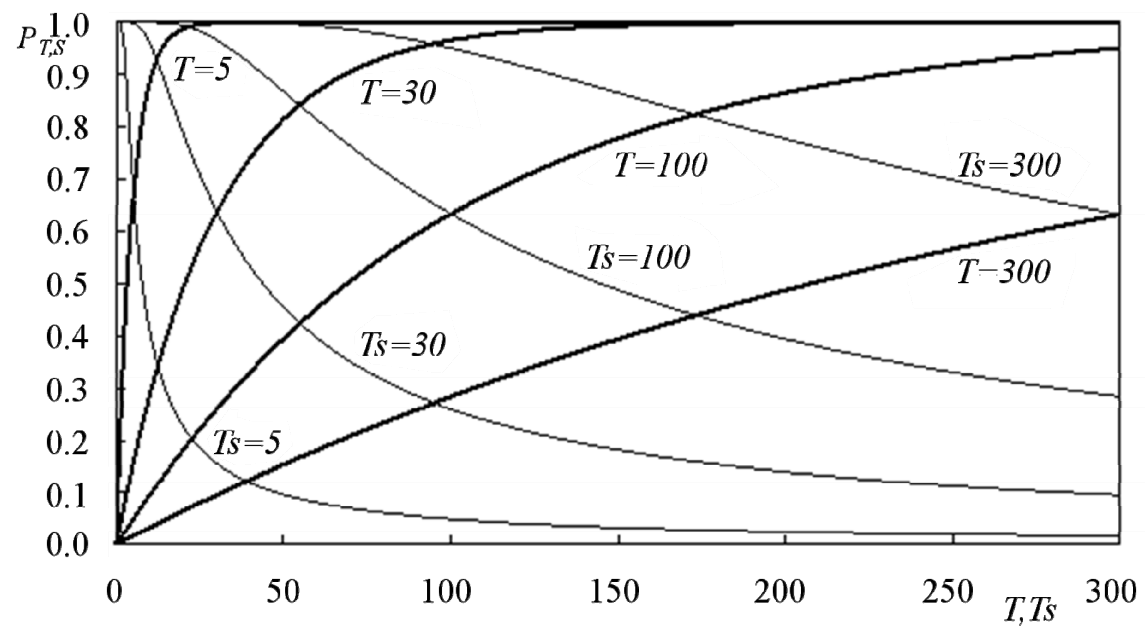

Figure 1: $\quad$ Probability $P_{T, S}$ from equation (9).

From the first series of curves, for each value of $T s$, the probability $P_{T, S}$ can be obtained that an event, characterized by a fixed return period $T$, can occur within $T s$ years. The intersection between the two series of curves provides the probability that the event will occur when the condition $T_{S}=T$ is true: it should be noted that the $P_{T, S}$ value has a small variability for values of $T_{S}=T>5$. Moreover, once the value of $T_{S}$ is fixed, it can be interesting to determine the return period $T$ referred to an admissible pre-selected probability $P_{T, S}$.

In Table 3 numerical values are reported of probability $P_{T, S}$ derivable from equation (9); the disposition of probability values is consistent with information that can be obtained from the risk matrix reported in Table 1. 
Table 3: Probability value from equation (9).

\begin{tabular}{|c|c|c|c|c|}
\cline { 2 - 5 } \multicolumn{1}{c|}{} & $T=5$ & $T=30$ & $T=100$ & $T=300$ \\
\hline$T_{S}=300$ & 1 & 1 & 0.951 & 0.633 \\
\hline$T_{S}=100$ & 1 & 0.966 & 0.634 & 0.284 \\
\hline$T_{S}=30$ & 0.999 & 0.638 & 0.260 & 0.095 \\
\hline$T_{S}=5$ & 0.672 & 0.156 & 0.049 & 0.017 \\
\hline
\end{tabular}

Indeed the risk increases as the probability of an event rises, considering such an event endowed with a potential hazard correlated both to a fixed return period and to a river band. In the final analysis, therefore, territorial planning and management activities can be facilitated by the introduction of the simple matrixes analysed, whose essential methodology links the flood risk to the river bands representing the largest flood-prone area in a given event.

\section{Conclusion}

Territorial planning aims to create an organic knowledge framework of the natural and anthropic phenomena that have to be controlled by harmoniously regulating present and future land use. This planning procedure needs to be managed by means of measures that will safeguard areas at flood risk, preferably defined on the basis of straightforward and easily applicable procedures that can therefore be used even by technical staff with no specific expertise in this field. On the other hand in order to avoid excessively challenging protection work for dimension and typology or form technical and economic point of view, periodical failures have to be admitted. However, these have to be contained within tolerable limits. In this context, the simple methodology illustrated in this paper for identifying matrixes that can characterise the risk level of flood-prone areas appears to be of particular utility. These matrixes are constructed using a limited number of parameters managed by simplified models. In general the criterion adopted is that damage derived from periodical floods is economically smaller than the interest of the budget economization from the execution of protection works (cost-benefit analysis). The matrixes express the risk through the value of the damage that vulnerable elements - with hierarchical priority for anthropic elements - are expected to suffer following the occurrence of an event of given hazard. Actually when human life is in danger the measures to be adopted have to respect more severe safety rules. It has to be noted, however, that the cost of the work is proportional to neither return period pre-selected nor to the consequent risk. As a consequence it appears useful to choose the return period for designing the protection work starting from a pre-selected admissible occurrence probability of flood event. The definition of the flood risk, moreover, starts from the analysis of the hydraulic behaviour of the various sections of the river to achieve the identification of river bands that characterise the areas endowed with a larger or smaller degree of flood hazard. The identification of 
such bands can be considered the basis for: (i) the calculation of the stream flow induced stresses; (ii) the choice and entity of the river protection works which can be both traditional and naturalistic. Efficiency of such naturalistic works is notoriously variable over time and it has to be compared, therefore, with the assigned return periods.

\section{References}

[1] Destra Sele Basin Authority, Provisional Hydrogeological Plan, Final Report, Regione Campania, Italy, 2002. (In Italian).

[2] US Department of Transportation - Federal Highway Administration, FEWSWMS-2HD - Finite Element Surface Water Modelling System: Two-Dimensional Flow in a Horizontal Plane. User Manual, Research, Development and Technology Turner-Fairbank Highway Research Centre, Publication No. FHWA-RD-88-177, 1989.

[3] Horritt, M.S. \& Bates, P.D., Evaluation of 1D and 2D numerical models for predicting river flood inundation, Journal of Hydrology, 268, pp. 8799, 2002.

[4] Förster, S., Chatterjee, C. \& Bronstert, A., Hydrodynamic simulation of the operational management of a proposed flood emergency storage area at the Middle Elbe River, River Research and Application, 24, pp. 900-913, 2008

[5] Siviglia, A., Repetto, R., Zolezzi, G. \& Tubino, M., River bed evolution due to channel expansion: general behaviour and application to a case study (Kugart River, Kyrgyz Republic), River Research and Application, 24, pp. 1271-1287, 2008.

[6] US Army Corps of Engineering, HEC-RAS User Manual Version 4.0, Hydrologic Engineering Centre, 2008.

[7] Yen, B.C., Open-Channel Flow Equations Revisited, Journal of the Eng. Mech. Division, ASCE, 10, pp. 610-621, 1973.

[8] Reed, J.R. \& Wolkfill, A.J., Evaluation of friction slopes, River 76 Symposium on Inland Waterways for Navigation, Flood Control and Water Diversions, Colorado State University, Colorado, 1981.

[9] Blalock, M.E. \& Sturm, T.W., Minimum specific energy in compound open channel, Journal of Hydraulic Division, ASCE, 107(6), pp. 699-717, 1981.

[10] Feldman, A.D., HEC Models for water resources system simulation: theory and experience, Advances in Hydroscience, 12, pp. 297-423, 1981.

[11] Konemann, N., Discussion on Minimum specific energy in compound open channel by Blalock ME \& Sturm TW, Journal of Hydraulic Division, ASCE, 108(3), pp. 452-464, 1982.

[12] French, R.H., Open-Channel Hydraulics, McGraw-Hill Book Com., 1985.

[13] Molinas, A. \& Yang, C.T., Generalized water surface profiles computations, Journal of Hydraulic Engineering, ASCE, 111(3), pp. 381$397,1985$. 
[14] Rossi, F., Fiorentino, M. \& Versace, P., Two component extreme value distribution for flood frequency analysis, Water Resources Research, 20(7), pp. 847-856, 1984.

[15] Ciaravino, G., Ciaravino, L., Grimaldi, G., Lombardi, G. \& Sorvino, L.S., Risk management in flood events, Flood Recovery, Innovation and Response, edited by D. Proverbs, C.A. Brebbia and E. Penning-Rowsell. Wit Transaction on Ecology and the Environmental, 118, pp. 175-183, 2008.

[16] De Wrachien, D., Mambretti, S. \& Sole, A., Risk analysis and vulnerability assessment in flood protection and river basin management, Flood Recovery, Innovation and Response, ed. by Proverbs D, Brebbia CA and Penning-Rowsell E. Wit Trans. Ecology and the Environmental, 118, pp. 3-15, 2008.

[17] Vis, M., Klijn, F., De Bruijn, K.M. \& Van Buuren, M., Resilience strategies for flood risk management in the Netherlands, Inter. Journal River Basin Management, 1, pp. 33-40, 2003. 